\title{
ACOMPANHAMENTO DE
}

\section{TURMAS NAS DISCIPLINAS DE PROJETO E CONSTRUÇÃO DE EDIFÍCIOS}

Modalidade: Experiência de ensino-aprendizagem BIM realizadas.

\section{DESENVOLVIMENTO}

Com o objetivo do compartilhamento da tecnologia e da disseminação do BIM, a LABIM decidiu fazer 0 acompanhamento das turmas das disciplinas de Projeto $\mathrm{e}$ Construção de Edifícios I e II da matriz curricular do curso de Engenharia Civil da UFCA durante 0 ano de 2019. Nessa perspectiva, diante do auxílio oferecido, diversos alunos foram beneficiados com ganhos de rendimento e produtividade nas atribuições acadêmicas, através da praticidade disponível no uso dos softwares BIM, para realização de

Figura 1: Alunos participantes do projeto

Participantes do Acompanhamento

- Total de Alunos a PCE 1 PCE 2

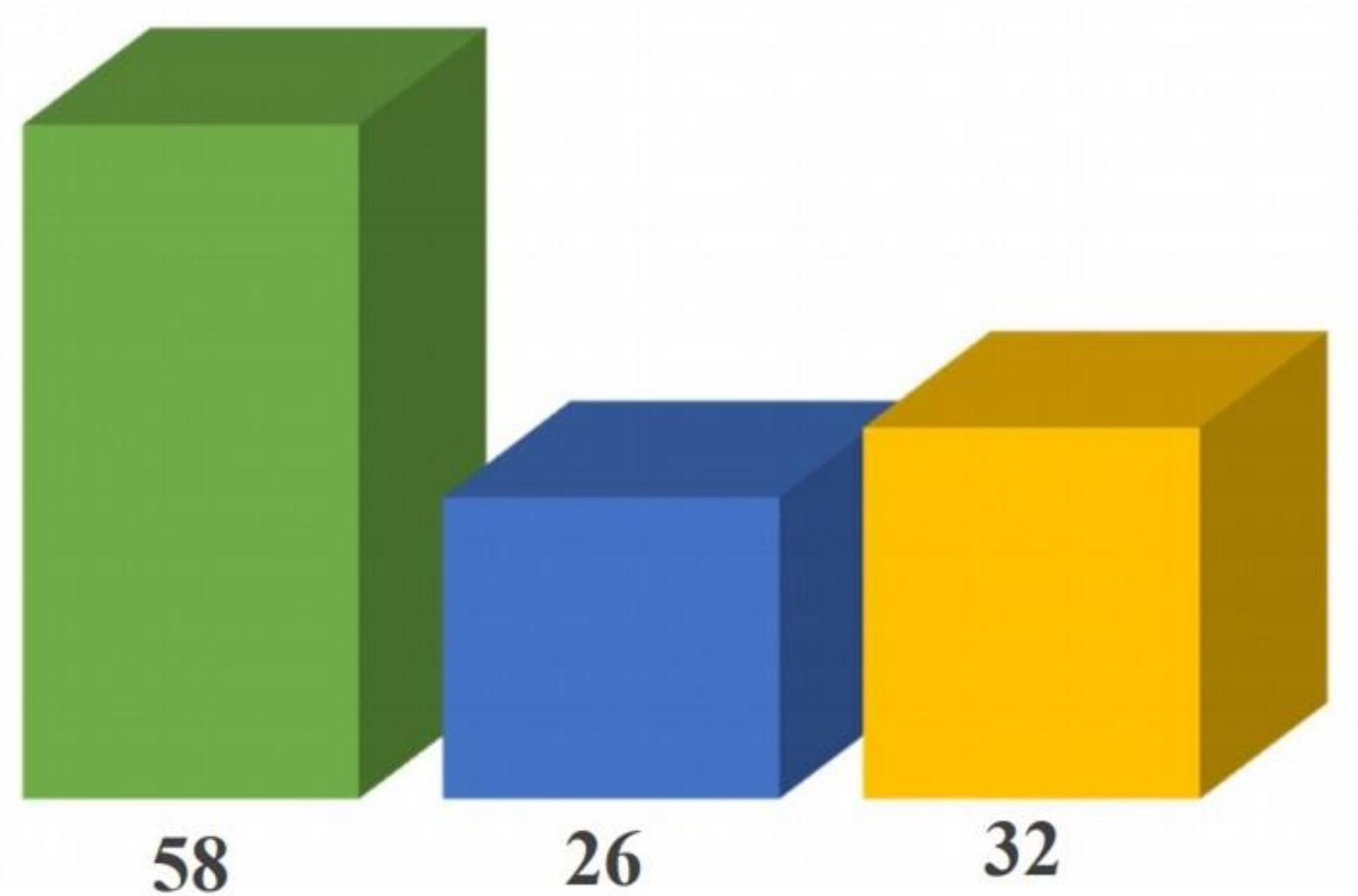

\section{LIÇÕES APRENDIDAS}

Notou-se por meio do acompanhamento que há um grande estímulo por parte dos alunos em aprender sobre o software Revit e sobre os conceitos do BIM. 0 projeto foi também um grande incentivo aos professores das disciplinas de projetos a estimularem o uso da metodologia BIM nos trabalhos realizados. Como não é atividades automatizadas. Aos alunos das disciplinas acompanhadas, foram dadas assistências na criação de cortes e fachadas, de alvenaria modular, de cobertas e escoamento de águas pluviais. 0 acompanhamento foi feito por meio de tira-dúvidas e capacitações para nivelar os estudantes dessas disciplinas. Houve também alguns dias reservados apenas para auxílio aos alunos com relação a utilização de softwares com foco nas suas ferramentas.

Figura 2: Aprovações PCE 1 E PCE 2

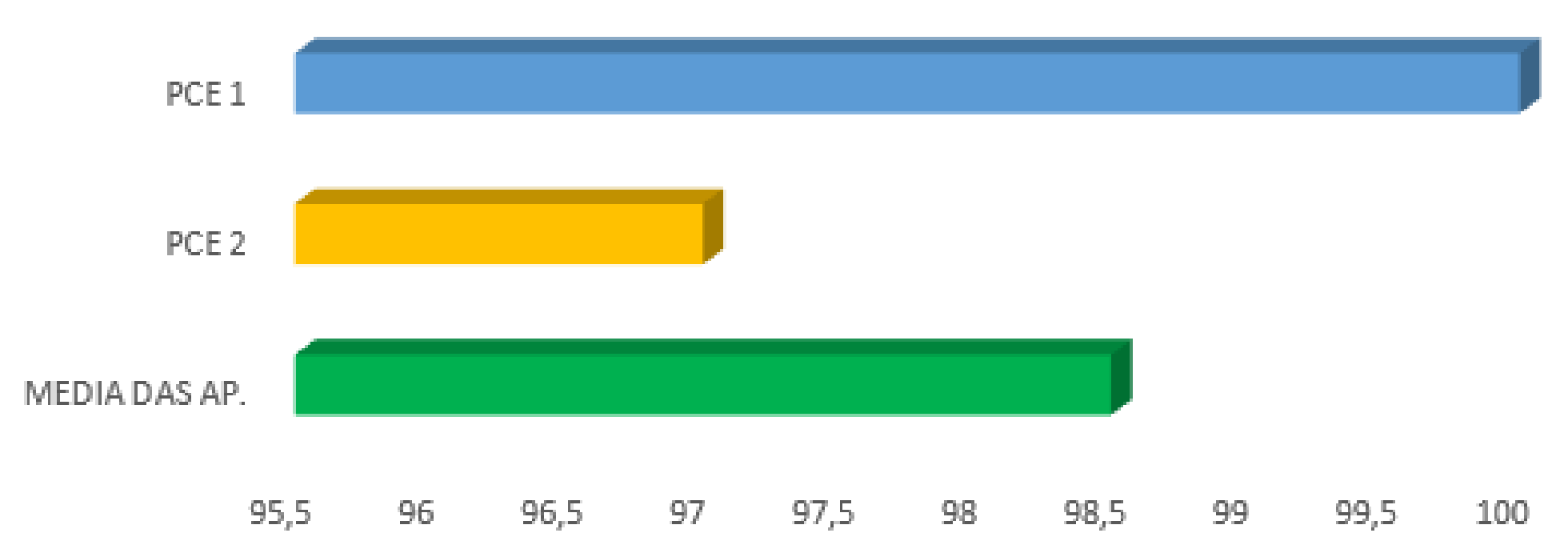

previsto no plano de ensino ministrar aulas sobre as ferramentas da tecnologia BIM, a liga pôde servir de apoio para essas disciplinas. Além disso, os alunos puderam compreender melhor a necessidade do ensino do BIM nas universidades e a importância da Liga para o curso de Engenharia Civil na Universidade Federal do Cariri.

Bruno Sampaio Moreira José Arthur Filgueira Felizardo Juan Carlos Vieira de Souza

1- UFCA,juan.sousa@aluno.ufca.edu.br 2- UFCA,arthur.filgueira@aluno.ufca.edu.br 3- UFCA,bruno.moreira@aluno.ufca.edu.br

\section{INTRODUÇÃO}

BIM é uma metodologia inteligente baseada em modelagem da informação utilizada por profissionais de arquitetura, da engenharia e da construção. Nesse sentido, softwares como Revit, aumentam bastante o rendimento em projetos devido a integração entre os modelos, a utilização da informação e o detalhamento do modelo construtivo. Isso posto, torna-se evidente a necessidade da inserção da tecnologia nas atividades curriculares, visando a formação completa dos futuros engenheiros e a modernização dos modelos construtivos como um todo. Nesse sentido, a LABIM (Liga Acadêmica de Building Information Modeling) implementou um acompanhamento voltado para alunos da Universidadade Federal do Cariri, objetivando melhorar 0 desempenho no uso de softwarese a difusão do conhecimento acerca do BIM.

\section{AGRADECIMENTOS}

À LABIM, pela disponibilização de dados e documentos para execução do trabalho, à orientadora Ana Verônica Gonçalves Borges pelo auxílio na produção e execução do projeto, e à PROEX por incentivar ações de extensão na universidade. 